\title{
Effect of improving spatial or temporal resolution with k-t SENSE acceleration in first pass CMR myocardial perfusion imaging Neil Maredia*1, Aleksandra Radjenovic ${ }^{1}$, Abdulghani M Larghat ${ }^{1}$, Sebastian Kozerke ${ }^{2}$, John P Greenwood ${ }^{1}$ and Sven Plein ${ }^{1}$
}

\begin{abstract}
Address: ${ }^{1}$ University of Leeds, Leeds, UK and ${ }^{2}$ Institute for Biomedical Engineering, University and ETH Zurich, Zurich, Switzerland
\end{abstract}
* Corresponding author

from 13th Annual SCMR Scientific Sessions

Phoenix, AZ, USA. 21-24 January 2010

Published: 21 January 2010

Journal of Cardiovascular Magnetic Resonance 20 I0, I2(Suppl I):O40 doi:I0.I I86/I532-429X-I2-SI-O40

This abstract is available from: http://jcmr-online.com/content/I2/SI/O40

(c) 2010 Maredia et al; licensee BioMed Central Ltd.

\section{Introduction}

First pass cardiac magnetic resonance (CMR) myocardial perfusion imaging (MPI) requires the acquisition of large amounts of image data in a short time. Acceleration techniques like $k$ - $t$ SENSE exploit spatiotemporal correlations to speed up data acquisition. In myocardial perfusion CMR $k$ - $t$ SENSE has been used to improve spatial resolution, temporal resolution or slice coverage with improvements of endocardial dark rim artefacts reported. To date, there has been no direct comparison between these strategies.

\section{Purpose}

To compare the effect of investing the speed-up afforded by $k$ - $t$ SENSE acceleration in spatial or temporal resolution.

\section{Methods}

Adenosine stress and rest MPI was performed using a 1.5 T Philips Intera system. Ten healthy volunteers were scanned on four occasions using a different saturation recovery gradient echo perfusion sequence at each visit (Table 1). The order of sequence utilisation varied for each volunteer.

Image analysis was performed on the middle slice. Image quality was scored 0-3 (0-poor, 3-excellent) and breathing artefacts noted by two readers in consensus. Dark rim artefact was assessed by: thickness (using electronic callipers), duration (frame count) and extent (area of artefact meas- ured by contouring and expressed as a percentage of myocardial area). Friedman Test and repeated measures Analysis of Variance Testing (with Bonferroni correction for pairwise comparisons) were used to compare non-parametric and parametric data respectively.

\section{Results}

Image quality at stress did not significantly differ between the sequences (table 2). At rest, the $k$ - $t$ Hybrid sequence showed highest quality. Rim artefact thickness was similar using REFERENCE and $k$ - $t$ Fast sequences but significantly lower using $k$ - $t$ High and $k$ - $t$ Hybrid sequences. Rim artefact extent was significantly higher for REFERENCE images, similar for $k$ - $t$ Fast and $k$ - $t$ Hybrid images and significantly lower for $k$ - $t$ High images. Although four-way comparison suggested a difference at rest, rim artefact duration did not differ between sequences by pairwise analysis at stress or rest. Breathing artefacts occurred in $57 \%$ of stress and $17 \%$ of rest $k$ - $t$ SENSE studies. No breathing artefacts were seen with REFERENCE data.

\section{Conclusion}

Although spatial and temporal resolution both influence the thickness and extent of dark rim artefact, maximising spatial resolution by $k$ - $t$ SENSE acceleration produces the greatest reduction in these parameters. This may lead to fewer false positive results using CMR MPI in a clinical setting. $k$ - $t$ SENSE remains sensitive to respiratory artefacts. 
Table I: Pulse sequence characteristics. (* assuming $340 \mathrm{~mm}$ field of view)

\begin{tabular}{lllll}
\hline Sequence Name & REFERENCE & k-t High & k-t Fast & k-t Hybrid \\
\hline Acceleration Method & SENSE & $k$-t SENSE & $k$-t SENSE & $k-t$ SENSE \\
\hline Acceleration Factor & 2 & 8 & 8 & 11 \\
\hline Training Profiles & - & 11 & 11 & 3 \\
\hline Number of slices & 3 & 3 & 3 & 192 \\
\hline Acquisition Matrix & 128 & 256 & 128 & $1.77 \times 1.82 \times 10$ \\
\hline Acquired Voxel Dimensions (mm)* & $\begin{array}{l}2.66 \times 2.66 \\
\times 10\end{array}$ & $119 \times 10$ & $2.66 \times 2.76$ \\
\hline Image Acquisition Time Per Slice (ms) & 117 & 64 & 109 \\
\hline
\end{tabular}

Table 2: Image quality and dark rim artefact results.

\begin{tabular}{|c|c|c|c|c|c|c|}
\hline & & REFERENCE & k-t High & k-t Fast & k-t Hybrid & $P$ value \\
\hline \multirow[t]{2}{*}{ Mean Image Quality Score } & Stress & 1.7 & 1.6 & 1.7 & 1.9 & 0.590 \\
\hline & Rest & 2 & 2.1 & 1.9 & 2.4 & 0.015 \\
\hline \multirow[t]{2}{*}{ Mean Rim Thickness (mm) } & Stress & 3.4 & 1.1 & 3.0 & 1.8 & $<0.001$ \\
\hline & Rest & 3.4 & 1.3 & 2.7 & 2.2 & $<0.001$ \\
\hline \multirow[t]{2}{*}{ Mean Rim Extent (\%) } & Stress & 16.1 & 2.2 & 6.0 & 4.6 & $<0.001$ \\
\hline & Rest & 14.5 & 1.7 & 5.0 & 4.7 & $<0.001$ \\
\hline \multirow[t]{2}{*}{ Mean Rim Duration (frames) } & Stress & 11 & 7 & $\mathrm{II}$ & 10 & 0.07 \\
\hline & Rest & 13 & 9 & II & 13 & 0.008 \\
\hline
\end{tabular}

Publish with Bio Med Central and every scientist can read your work free of charge

"BioMed Central will be the most significant development for disseminating the results of biomedical research in our lifetime." Sir Paul Nurse, Cancer Research UK

Your research papers will be:

- available free of charge to the entire biomedical community

- peer reviewed and published immediately upon acceptance

- cited in PubMed and archived on PubMed Central

- yours - you keep the copyright
BioMedcentral 